\title{
A Collaboration Between Industry and University Focusing on the Making of Edutainment Apps
}

\author{
Barbara Bruschi \\ Dept. of Philosophy and Educational Sciences, University of Turin. \\ Via Gaudenzio Ferrari 9/11, 10124, Torino. Italy \\ barbara.bruschi@unito.it
}

\begin{abstract}
The massive diffusion of mobile technologies, distinctive of the latest years, has commanded to reflect upon the educational and social impact which such systems are able to have, especially on an audience of youngsters. Alongside questions trying to establish which features make to a good app for children, there is a debate upon which educational principles should be a guide to the use of these media, having in mind a world increasingly founded on equity and sustainability.
\end{abstract}

This paper presents an Italian experience of collaboration between private industry and university planning and implements apps for children between 3 and 6 years old. The first part contains an analysis of the various assumptions on which the collaboration between the two partners is funded, with a highlight on the sharing process of the cultural and social goals to achieve. The attention then moves on to the collaboration process with a focus on the work organisation and the assigning of roles. Special concern is given to the products' evaluating and certificating process, conducted through the identification of a range of quality principles of the apps. The final part concentrates on the relationship between sustainability and media education, considering the future diffusion of a technological culture marked on ethics.

\section{Keywords}

Sustainability; Technology Sustainable Consumption Education

\section{Introduction}

Since early considerations on educational media, the necessity to act on the productive process of the media industries was confirmed: so doing, the educational side of the messages created could be valued and the quality of the representations offered could be verified. Len Masterman, one of the founding fathers of the media education way of thinking, has always referred to the media production systems as an "industry of consciences"; with these words Masterman intended to stress their ability to intrude into the individuals' processes of analysis and interpretation of reality
[Buckingham 2006]. Starting from these principles, throughout the years, different experiences of collaboration between the research area and that of the media production have taken place, with focus on two main elements: a higher ability of the products (made according to educational principles) to penetrate markets; the interest shown by the public for those products which lay within the logic of a sensible and conscious consumption.

With the diffusion of mobile technologies, the necessity to make consumption choices not exclusively geared from the market, but based on different educational and social principles has grown. Specifically, parents who wonder which might be the best technological choices to make regarding their children raised in number, especially when the children are still of a preschool age; likewise, the reflection on the need to adopt a sustainable behaviour receives more and more consent.

These topics gain significant relevance when applied to products for children. First of all, there is the safety matter: when parents buy a product for their children (especially when the children are kid), they want to be reassured that there are no risks for health or psychic equilibrium. What is even more important, families increasingly regard technologies not so much as hobby, but as a tool for cognitive enhancement or at least as an educational opportunity. In particular the attention of the new app market towards mobile technologies is directed to both the apps' quality and to the changes that these can generate in games, readings and, generally, in the creative expression [Keskin and Metcalf 2011]. This derives from the fact that apps enable new ways of interaction [Druin, 2009] with the technological device and they contribute to transforming the technological experience and that of reading, playing, narrating and exploring. For this 
reason as well, it is important to ensure the educational value of the products available for children and to guarantee features which may enable a fun, engaging and pedagogically correct fruition.

The experience here reported originates from these premises and it has involved the Departement of Philosophy and Educational Sciences of the University of Turin and a small Italian company, Jekolab, born with the aim to design and create educational apps for children.

\section{The University Face to Face with the Production: Pedagogical Principles and Socioc ultural Intents}

The collaboration with the production world was instantly perceived as an opportunity to see some pedagogical principles in practice. Besides, it was allowed to actually participate in the industry of children entertainment, so contributing to the diffusion of that culture of awareness, educability and sustainability which has been characterizing, for several years, educational research in the technological area. In this way, the university had a chance to test some educational hypothesis, and to play a part in the merging of the various areas of knowledge revolving around the game and education industry. Collaborating with Jekolab has helped in the development of a technological culture founded on quality and of educational strictness requirements. Even more importantly, it offered a privileged field of action-research. The starting point consisted in the idea that the building of a good media culture [Shaffer 2012] lays on consumption just as well as on production. As a matter of fact, it is essential to initiate some media education actions involving families, children, teachers and educators. Similarly, working closely with the media producers is crucial: in this way, the productive process as well might not simply be a passage towards profit, but in fact it represents a place for cultural growth and social development. The intent is to give life to an industry which might place values and ethics alongside profit, especially considering that the most recent technological scenarios have a tendency to present themselves as yet another exaltation of quantity at the expense of quality, of consumption to the disadvantage of the actual need.

The realities taking shape in the light of technological evolution and the media market set the media pedagogy in front of new educational challenges among which are:

- Contribute, with new educational proposals, to the battle against digital consumerism. This means developing technology diffusion policies which, aside from answering to the logic of profit, might be the result of accurate processes of choosing the most suitable solutions to adequately satisfy the new educational needs. Solutions must be found in accordance with the "de-economizing" process advocated by the French sociologist Latouche (Latouche 2002).

- Educate and train families to a judicious consumption and to media awareness, especially when dealing with the new technological applications. Media Education has always tried to stimulate in teachers and in parents a judicious awareness necessary to make media choices suitable to the reference population [Felini 2012]. Today this awareness must be enriched understanding the realities generated by to the diffusion of the new digital technologies [Silverstone 2006; Oehlkers and Di Donato 2012].

- $\quad$ Aid the development of productive realities oriented towards sustainability and rights (especially those of workers). This means favouring the productive realities based on work dignity, on respect for the environment and for consumers

- Establish proactive and long-lasting connections between the educational world and the new media industry. In the audio-visual field, the link between production world and educational institutions has enabled, in some cases, to improve the format quality; a similar path should be desirable in the various areas of digital. This is a particularly delicate point because it implies a specific vision of the relationship between the two universes, based on the principle of non-exclusion: trying to remove certain realities or assuming a decrease in the speed of technological innovation is of no use. What can be done is co-manage these processes so that the market might not swallow up the consumers. On the contrary, hopefully a function system may be created for the well-being of both parties: the consumers could benefit from the consumption of adequate digital products and the market could develop according to an ethical and sustainable environment.

\section{The Industry Face to Face with the Educational World: a Path Between Creativity and Sustainability}

Media industry and university working together is by 
no means news: there have been several cases of big companies who partly founded their success on the interaction between the educational research world and the industrial production (especially when the products were for a group of exceptionally sensitive consumers, such as children in preschool age). Although this kind of interaction is by now a wellfounded choice for the big brands, the same cannot be said for the smaller businesses which decide to step into the market of educational apps. On the one hand, for this type of firm, the encounter with the academy represents an added value: it allows entering the market with a product edited from several prospects and, most importantly, in accordance with the guidelines of educational research. On the other hand, however, as it will be clarified further on, it also implies a critical factor as far as expenses are concerned. Aware of such a situation, Jekolab started the experiment with the desire to guarantee quality products to the public and so tried to structure its productive processes with innovative methods.

Jekolab (www.jekolab.com/) is a company founded in Turin - a big city in the North of Italy - in 2011, specialised in the making, production and commercialisation of educational apps for children (age 3-12). Its founders define it as "a creative laboratory where applications wholly Made in Italy are developed".

From the start, the objective of the business has been to produce pedagogically valid and ethically sustainable apps. The driving idea of the project lays in the belief that the commercial purposes do not constitute an obstacle, neither in the creation of products for the development of children nor in the orientation towards a judicious and educational consumption of media texts [Andreoletti 2012; Alper 2013]. For this reason, the company, from the beginning of the activity, has sought a collaboration with the university, in order to set up a multidisciplinary team of people closely working together during the various stages of the fabrication of the apps. The work group has thus involved designers, graphic designers and programmers, together with a Ph.d in Educational Technology Research and a Professor of Teaching and Learning Technologies from the Department of Philosophy and Educational Sciences.

\section{The Collaborative Process: from Choosing the Titles to Planning}

One of the first matters Jekolab dealt with concerned the type of app to make. The prioritty was not so much to identify a type of commercially appealing product, rather than define the educational goals to reach through the apps. At the end of an analysis of the context and of the audience, Jekolab divided its production into three main areas:

- $\quad$ tales, a series of interactive tales

- "libroblò", interactive theme books

- "ditamatte", interactive collections for games and creativity

All the products were designed for children between 3 and 6 years old and created starting from the same assumptions. However, only the tales have been certified by the university: it was considered suitable to focus the research activities on the most architecturally elaborate products and on those with complex contents and potential educational impact.

Four tale-apps belonging to the classics of children's literature have been realised:

The Three Little Pigs, Rapunzel, Snow White and the Seven Dwarfs and Trip to the Moon. The choice of the titles to convert into apps fell on classic tales because this type of narration is approved by the families and greeted by children; plus, its texts are significant in the educational path of youngsters and in the approach to reading.

The comparison with the classic repertoire conveyed a positive element. It allowed to work on a well-known and loved product. Nevertheless, it also forced a parallel with the representations of which the publishing market and the media are filled, a field which sees the big names in publishing for children in first row. It was not about overtaking the competition, but offering a fresh and original version of tales which could highlight the innovative features of the technological device (with a focus on learning and interactivity, rather than on the special effects).

On the operational side, the collaboration was structured in three major moments: the designing, the implementation and the certification, or so to say, the final act of assessment of the product, in line with a series of standard parameters (estimated to be essential for the quality of educational apps and identified according to the literature in the field) [Proffitt 2012; Sharples et al. 2012].

Basically, the work was divided in this way:

Stage 1. Choosing the tale. Singling out the text to transpose into app was the result of an intense negotiation among the different figures; the elements 
to consider were several and they required different professional skills. Educationally speaking, experts tried to promote those narrations which allowed to "work" on specific themes and which were considered important for the development of children (for instance, values).

Stage 2. Making of the storyboard. The Ph.d in Education Technology personally took care of the draft of the storyboard through which the story was expressed in interactive scenes. Interactivity is, of course, one of the fundamental elements of apps and for this reason it requires particular attention and regular effectiveness and usability checks. In this paper, this phase also includes the study of multimedia elements, like the narrating voice, music and dynamics of some components.

Stage 3. Once the storyboard was completed, it was shown to the Professor of Technologies who verified its pedagogical validity: if the identified target could actually use it and the narrative effectiveness. A further test was then made by the whole of Jekolab staff.

Stage 4. Graphic production of the tablets and checkup. The narrative products for children, whatever the category is, demand a scrupulous care in graphics. The majority of children turning to app-tales are not yet able to read and they concentrate mainly on features: images and interactivity. That is why, it is essential to make accurate choices from various points of view, while focusing on creating a welcoming and stimulating environment. For these reasons, all the tablets have undergone thorough checks by the experts.

The app implementation stage was devolved upon professional programmers and the result was by and by evaluated by experts.

Clearly, the work organisation is very similar to the one used in the fabrication of other products, not even exclusively for children. However, it is important to remember that apps differ from videogames and educational software; for instance, there are other kinds of support, methods and occasions for use.

Certification assessed if the guidelines (fundamental for the quality of an educational app) had been followed, if during the designing and the making stages it had been possible to attain to the quality principles. Among the fundamental criteria to guarantee an app's quality, some have been singled out as especially significant:
- target, meaning the correspondence between the age range for which the app is designed and the way it has been made. This correspondence was realised starting from the Piaget's developmental theory. The mental and physical development tends to change interests, skills, the way to employ cognitive device and metacognitive strategies. Inspired by the work conducted by Piaget is possible to identify three specific age groups to consider: 3-5 years old/6-9 years old / 1012 years. The first two groups are particularly complex while for the target $10-12$, the project plan (interface design, type of interaction) may adopt strategies similar to those taken into account for the realization of products addressed to a more adult public.

- chance to personalise the apps, for example choosing a language;

- differentiation in the manner the contents were presented, starting from Kolb's theory of cognitive styles;

- isomorphism between the interactivity gestures and the activities carried out;

- type of exploration and reference of the narrative. It is fundamental to create a space in which the User Experience is natural. Because of that, it can be appropriate to use an immediate and intuitive metaphor. This principle is even more central if referred to as children who do not yet have skills in reading/ writing and for which the metaphor is the main meaning that they are able to grasp. In the app-tales, we must just follow the story in order to have metaphor and navigation context easy to learn and explore. However, graphic solutions, interaction models and gestures were delicate items that have imposed accurate choices;

- variety in the multimedia contributions and internal coherence;

- type and variety of forms of interaction;

- satisfaction and fun. The usability of technological devices is crucial for user satisfaction. However, especially for younger children the satisfaction does not necessarily coincide with usability, but with fun. A challenge must be developed so that the app deserves the attention of children, that will feed their satisfaction and therefore generate fun. We should imagine activities in which it is necessary to solve a difficult initial situation (eg a game) or simply move from a chaotic or 
incomplete one to a more orderly one (puzzles, coloring, etc ...) .

It is expected that synergies among these elements would contribute to the realization of app valid from the educational point of view and that would respect the needs of children in cognitive development.

Although the attention has been particularly focused on the above mentioned points, it must be reminded that the evaluating process always began from the most general principles of media education: the importance and the value of the representations created and spread through the media text in question. For example, deciding to portray a character according to certain characteristics instead of others does not always depend on quality factors; and it may depend on features concerning genre differences or prejudicial forms of representation of certain categories. In the same way, the decision to provide tale representations different from the market standard is not about the quality of the product, rather than the desire to provide the public with a vision other than the monopoly imposed by some brands in the sector. In some ways, it is possible to say that these are the most delicate and difficult elements to handle in a production context where educational effort and the logic of profit must be combined. Furthermore, it must be said that the project involved a small business, a productive enterprise with limited (compared to firms in the big media industries) financial resources and operational availability. This last characteristic is a factor of great interest. On the one hand, the creative process was able to regain craftsman work traits thereby favouring attention to details; on the other hand, in some cases, choices were strongly influenced by the need to limit costs.

While this contribution is published, implemented apps will be evaluated through focus groups that will see children in the interaction with the educational products through the iPad.

Through this phase of the research we will look for answer to questions such as:

1. are our gestures appropriate to the target audience?

2. Are children able to immediately detect gestures needed to interact with the interface?

3. Does kids demonstrate, through verbalization, to have fun?

4. At the end of the activuty are they able to tell what happened during the interaction?

5. Are they able to identify streategies to activate all suggested systems of interaction?

\section{Certifying Educational Quality: a Process of Cultural Rethinking}

Product certification has been, for some time already, a common practice and well-received by consumers. This, however, does not imply that the meaning given to this process and its value are always clear. Jekolab's choice and the University's sharing of this choice intended to contribute to a cultural change, specifically, in the making of media products for children and, more in general, in the world of media and technology consumption.

Therefore, at the centre of the productive process are the elements analysed in the previous paragraph, in addition to a series of ethical assumptions considered particularly pertinent especially in the context of mobile technologies which, for several reasons, change the relationship with the digital technologies and their consumption.

Here follow some of these elements.

\section{Childhood and Media Consumption}

As it is known, for some time, minors have been in a prominent position in the market. Frequently it is to them that brands turn to, promoting products for adults, rather than for children and teenagers. Minors are considered the true technology decision-makers. An intervention must, therefore, take place to modify this type of approach and to educate the new generations towards a judicious and conscious consumption [Blewitt 2009]. It is necessary to spread consumption models, sustainable and adequate to the world of today: and they ought to be respectful of people (the workers), environment, and especially of the consumer itself. If we consider the market of apps for minors, we can notice, aside from a wide and constantly growing availability of products, some inconvenience elements. First of all, many apps do not have any meaning or utility: they simply represent an electronic diversion which passes on a wrong image of the employment of technologies and of the consumption of technological products (it is useless, but I must have it because it is very easily available and it is free). A great number of apps are sold as "inapp" purchase (a solution which enables developers to sell additional components of existing apps), so activating in kids an educationally incorrect mechanism of constant buying. Many products are available at extremely moderate prices or even for free, their quality level is often very low, but they stimulate 
a very little controlled and almost bulimic consumption: download is available regardless of the need, quality and the final value of the gesture. Jekolab expressed, through its decisions, the will to avoid these mechanisms and, instead, favoured an idea of profit linked to the value of the product and to the respect for the consumer.

\section{Proposal of a New Logic of the Product Essentially Based on the Principles of Development and of Individual and Social Growth}

This is, of course, in continuity with what has been stated before and it can now be classified as one of the most demanding elements with which the firm, and consequently its work team, had to deal with. All the created products are a result of an important educational project which has, at times, required costly investments. The availability of a multispecialised team; choosing to create solutions aiming at stimulating the cognitive and meta-cognitive development of the child may be respectful of his/her needs; the will to put the educational value in first place. All these are poorly winning factors on the investment upturn perspective. Especially because the relationship established by many consumers with the new devices is still immature and guided by impulse, more than by rationality.

\section{Collaborating with Families}

Jekolab decided to establish a special relationship with the families, putting at their disposal the "Question room": an online space where to ask university experts questions on the educational use of technologies. The activation of this service has a double aim: trying to build, within the web, a safe place where to find scientifically valid answers to questions concerning education and new technologies; establish a connection with the families based (besides consumption) on trust and collaboration. This choice is in continuity with the above statements and consistent with an innovative vision of productive realities.

\section{A Precise Action by the Media Industry Oriented towards Shared Educational, Economic and Social Values}

This has been repeatedly declared, but it is considered to be the real added value of the experiment carried out by Jekolab and its work team. As anticipated, the consumer's education alone cannot be sufficient to modify the market. Also the producers must adopt different strategies and quality policies, especially when dealing with a peculiar public, such as that of minors. It contributes to diffusing a media industry image active in limiting its commercial part in order to retrieve a "service" context with concern for the consumer; and this kind of image, in the long run, surely wins and it is the only possible solution to ensure compliance with a fundamental ethical position.

\section{A "Controlled" Release of Apps Opposed to the Logic of Technological Obsolescence}

The issue is not new, however with mobile devices is has grown to considerable size, with a significant social and cultural impact. Many products are obsolete already from the start, their life is ephemeral and exclusively determined by the necessity to constantly produce something new which may replace the previous product. Every day hundreds of new apps are released, some of which will be substituted in such a short period of time that any transformation or change cannot be justified. These apps seem to be created with the aim to continue to fuel a frenetic and neurotic mechanism of production and consumption. Considering these premises, Jekolab has focused on stability: it has offered a "controlled" release of the apps according to a time scan which might give the consumer the necessary time to know and take full advantage of the product before buying a new one. Even the choice of the tales is partly motivated by this characteristic: narrations do not "get old" quickly and they allow significantly slower time of use than other products.

\section{Conclusions}

The first goal to be reached is the public recognition given to some of the products: the tale The Three Little Pigs won the prize "Alberto Manzi" for educational communication - an Italian prize of great prestige - , proving that educational tasks can be fulfilled also through an app.

Also the press has widely appreciated the productive environment designed by Jekolab, constantly emphasizing the educational value of the products and the pedagogically valid mission of the brand.

For educational research, this experience was allowed to comprehend the fundamental aspects of the relationship between the media industry and education; which has led to highlighting the crucial elements of such relationship and the traits on which, in the future, efforts must be directed, especially those of the education experts.

Among the critical elements, it can be noted, in 
particular, that:

- a lot of work must be done on the public in order for it to learn to follow a "disciplined" behaviour when dealing with media products. This refers to the necessity for buyers to choose products according to value and quality principles, not simply depending on the cost. There is still some way to go before reaching the awareness goals which should guide every purchase, but change is possible;

- in this area, the market is still completely oriented towards profit and pays little attention to quality. Control policy, especially on products for minors, has still some weak points. It is based on general criteria (summarized in the Pegi codex), at the expense of broader elements of education, values and ethics.

More in general, it can be said that the real cultural change will take place only when concepts as sustainability and sensible consumption will actually be at the centre of the individual and large scale productions policies. Besides, an aid from the governments will be fundamental, through concrete actions supporting the brands moving in this direction.

\section{REFERENCES}

Alper, Meryl. “Developmentally appropriate New Media Literacies: Supporting cultural competencies and social skills in early childhood education". Journal Of Early Childhood Literacy, 2 (2013): 175-196. doi:10.1177/1468 798411430101

Andreoletti, Massimiliano. “Gioco e videogioco: riflessioni tra educazione e intrattenimento", in Video game education. Studi e percorsi di formazione, edited by Damiano Felini, Edizioni Unicopli, Milano 2012

Blewitt, John. “New media literacy. Communication skills for sustainability". In The handbook of Sustainability literacy. Skills for a changing world, edited by Aaron
Stibbe, A.Cornwall: TJ International, 2009

Buckingham, David. "Media Education. Alfabetizzazione, apprendimento e cultura contemporanea". Trento: Erickson, 2006.

Druin, Allison. "Mobile technology for children : designing for interaction and learning". Boston : Morgan Kaufmann Publishers/Elsevier, 2009

Felini, Damiano. “Videogame education. Studi e percorsi di formazione". Milano: Edizioni Unicopli, 2012.

Keskin, Nilgun Ozdamar, and David Metcalf. "The current perspectives, theories and practices of mobile learning". The Turkish online journal of educational technology, 10, 2, 2011, 202-208.

Latouche, Serge. "Il pensiero creativo contro l'economia dell'assurdo". Bologna: EMI, 2002

Proffitt, Brian. "iPad for kids : using the iPad to play and learn". Boston: MA Course Technology PTR, 2012

Sharples, Mike, and Josie Taylor, and Giasemi Vavoula. "Towards a Theory of Mobile Learning". Accessed October 3, 2013 - http://www.mlearn.org.za/CD/papers/ Sharples20Theory\%20of\%20Mobile.pdf

Shaffer, David Williamson, and James Paul Gee. "Before every child is left behind: How epistemic games can solve the coming crisis in education" Accessed October 3, 2013 - http://coweb.wcer.wisc.edu/dws/beforeeverychild. pdf

Silverstone, Roger. " Media and Morality: On the Rise of the Mediapolis". Cambridge: Polity Press, 2006

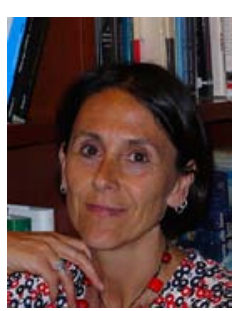

Barbara Bruschi is professor in Education Technology at the University of Turin in Italy. She received the BA degree in Pedagogy from the University of Turin in 1991. Her research interests include technology education and media education. 